\title{
ISOLATION OF HUMAN CARBONIC ANHYDRASE B AND C AND APOCARBONIC ANHYDRASE BY AFFINITY CHROMATOGRAPHY
}

\author{
by \\ JACK T. JOHANSEN \\ Department of Chemistry, Carlsberg Laboratory \\ Gamle Carlsberg Vej 10 - DK-2500 Copenhagen, Valby
}

Keywords: Human carbonic anhydrase, Apoenzyme, Isoenzymes, Affinity chromatography

Human carbonic anhydrase $B$ and $C$ have been purified in high yields by affinity chromatography, using two different affinity gels, incorporating the potent benzenesulfonamide inhibitor, but coupled to Sepharose through different sspacer-arms $\star$. Although both affinity gels bind carbonic anhydrase $B$ and $C$ quantitatively, they exhibit different binding capacities. Sepharose-glycyl-L-tyrosine-azobenzenesulfonamide was used to separate the mixture of isoenzymes from the bulk hemoglobin in the hemolysate of human erythrocytes. This affinity gel had a capacity of $15 \mathrm{mg}$ of enzyme pr. $\mathrm{ml}$ packed gel. The isoenzymes were eluted with thiocyanate an inhibitor of carbonic anhydrase.

The mixture of hemoglobin free isoenzymes was separated efficiently on a Sepharose-ethyl (p-carboxybenzenesulfonamide) carboxamide affinity gel by exploiting the difference in binding strengths for the B-and C-enzyme, respectively. Furthermore, the affinity gels could be used to separate the apoenzyme from the zinc enzyme.

\section{INTRODUCTION}

Purification of human carbonic anhydrase isoenzymes, carbonic anhydrase $B$ and $C$, from human erythrocytes can be accomplished using DEAE-Sephadex chromatography to separate the carbonic anhydrase from the large amounts of hemoglobin and also to separate the isoenzymes from each other (2). However, large-scale preparation using this procedure requires large columns and is laborious and time consuming. Hence, searches for new procedu- res based on affinity chromatography were investigated. Numerous studies have shown that aromatic and heteroaromatic sulfonamides are specific and strong inhibitors of carbonic anhydrase (9). Furthermore, the effect of $\mathrm{pH}$ on the binding constants, the differences in the binding constants for the two isoenzymes, the isoenzyme dependent inhibition by anions and the competition between anions and sulfonamides for the same binding sites are known in great details (9). These properties suggest 
that sulfonamide inhibitors would provide excellent ligands for the synthesis of affinity gels for carbonic anhydrase, since both the conditions for ideal adsorption and elution of the individual isoenzymes theoretically are attainable. FALKBRING et al. (6) and WHITNEY (13) have previously described the isolation of carbonic anhydrase $\mathrm{B}$ and $\mathrm{C}$ by affinity chromatography, employing p-aminobenzenesulfonamide coupled to Sephadex and p(aminoethyl) benzenesulfonamide coupled to Sepharose, respectively. However, these affinity gels exhibit a relatively low capacity for carbonic anhydrase, and hence these are not suitable for larg-scale procedures.

The present paper describes the synthesis of two improved affinity gels which basically have the same ligand, benzenesulfonamide, as described by FALKBRING et al, (6) and WHITNEY (4), but differ in the nature of the "spacer-arm". The Sepharose-Gly-Tyr-(p-azobenzenesulfonamide) affinity gel exhibits very high binding capacity for carbonic anhydrase, and is used to separate the mixture of isoenzymes from the bulk amount of hemoglobin. In addition, this affinity gel has the additional advantage of its red color, which enables visual estimation of its coupling efficiency, as well as the slow leakage of the ligand with time. Furthermore, due to its strong binding of carbonic anhydrase, it can be used in a batch-wise procedure. In contrast to this affinity gel another gel, Sepharose-ethyl(pcarboxybenzenesulfonamide) carboxamide, has low capacity, and can not be used in a batchwise procedure. However, this affinity gel exhibits much stronger affinity for the $\mathrm{C}$ enzyme than the $B$ enzyme. This specificity was exploited to separate a large amount of an isoenzyme mixture on a relative small column. After the present work was completed OSBORNE and TASHIAN (11) described the preparation of an affinity gel for carbonic anhydrase, in which (2,3 diaminophenyl) azobenzenesulfonamide was coupled to $\mathrm{CM}$ -
Sephadex, resulting in a gel with a capacity very similar to the azobenzenesulfonamide gel reported in the present paper.

Human carbonic anhydrase contains one gram atom of zinc per molecule, which is essential both for enzymatic activity and strong sulfonamide binding (4). Hence the affinity gels can also be employed to prepare metal-free apocarbonic anhydrases.

\section{MATERIALS AND METHODS}

Sepharose 4 B was obtained from Pharmacia, Uppsala, Sweden, Cyanogen bromide and pcarboxybenzenesulfonamide from Aldrich, Milwaukee, U. S. A. p-aminobenzenesulfonamide, 1-ethyl-3-(3-dimethylaminopropyl) carbodiimid-HCl $(E D C)^{1}$ and glycyl-L-tyrosine from Sigma Chemical Company, St. Louis, U. S. A. and ethylene diamine from Merck, Darmstadt. Human erythrocytes were obtained through the courtesy of Dr. O. Drachmann at the Blodbank, Københavns Amts Sygehus. Two sulfonamide affinity gels, Sepharose-GlyL-Tyr-azobenzenesulfonamide and Sepharoseethyl(p-carboxybenzenesulfonamide) carboxamide, respectively, were synthesized and used as affinity columns for the isolation of human carbonic anhydrase $B$ and C. Both the Sepharose-Gly-L-Tyr and Sepharose-ethylamine were prepared by the cyanogen bromide procedure, essentially as described by Cuntrecasas (5). Sepharose-Gly-Tyr was prepared from Sepharose 4 B freshly activated with cyanogen bromide $(180 \mathrm{mg} / \mathrm{ml}$ packed Sepharose) by coupling with Gly-Tyr $(5 \mathrm{mg} / \mathrm{ml}$ packed Sepharose) in 0.1 M-sodium bicarbonate, $\mathrm{pH}$ 9.5. The affinity gel was obtained by diazotization of p-aminobenzenesulfonamide and coupling of this compound to the Sepharose-Gly-Tyr. p-aminobenzenesulfonamide $(0.3 \mathrm{~g})$ was suspended in $120 \mathrm{ml}$ of icecold $1 \mathrm{M}-\mathrm{HCl}$, and to the suspension was added $0.9 \mathrm{~g}$ of sodium nitrite in $45 \mathrm{ml}$ ice-cold water.

The following abbreviations have been used: HCA, human carbonic anhydrase; HCAA, human carbonic anhydrase A; HCAB, human carbonic anhydrase B; HCAC, human carbonic anhydrase $C$; EDC, 1-ethyl-3-(3-dimethylaminopropyl)carbodiimid-HCl; SA-Sepharose, Sepharose-Gly-L-Tyr-azobenzenesulfonamide; SESepharose, Sepharose-ethyl (p-carboxybenzene-sulfonamide) carboxamide; Gly-L-Tyr, glycyl-L-tyrosine; Trissulfate, 2-amino-2(hydroxymethyl)-1,3-propandiol titrated to the desired $\mathrm{pH}$ with sulfuric acid. 
After 10 minutes of reaction the diazotized benzenesulfonamide was poured into a $600 \mathrm{ml}$ suspension, containing $300 \mathrm{ml}$ packed Sepharose-Gly-Tyr in 0.2 M-sodium bicarbonate $\mathrm{pH}$ 8.8. The $\mathrm{pH}$ was adjusted to 9.5 with 1 $\mathrm{M}-\mathrm{NaOH}$ and, after gentle stirring for 3 hours at room temperature, the coupled red Sepharose derivative (SA-Sepharose) was washed with 10 liters of water and 2 liters of 0.05 M-Tris- sulfate $\mathrm{pH}$ 7.6.

The Sepharose-ethylamine derivative was prepared by adding $115 \mathrm{ml}$ of an aqueous solution containing $15 \mathrm{ml}$ ethylene diamine, adjusted to $\mathrm{pH} 10$, to $100 \mathrm{ml}$ freshly activated packed Sepharose. The affinity gel was prepared by coupling p-carboxybenzenesulfonamide to the Sepharose ethylamine by the carbodiimide method. One hundred mililiters of wet packed Sepharose ethylamine was suspended in $400 \mathrm{ml}$ dimethylformamide containing $\mathrm{l} \mathrm{g}$ of p-carboxybenznesulfonamide. EDC ( $5 \mathrm{~g}$ in $30 \mathrm{ml}$ water $\mathrm{pH} \mathrm{4.7)}$ was added slowly, and the $\mathrm{pH}$ maintained at $\mathrm{pH}$ 4.7. After 20 hours of reaction at room temperature the affinity gel, Sepharose-ethyl(p-carboxybenzenesulfonamide) carboxamide (SE-Sepharose) was washed with dimethylformamide and a large volume of water.

For preparation of human carbonic anhydrase isoenzymes, the erythrocytes were washed twice with $0.9 \% \mathrm{NaCl}$ and then hemolyzed by addition of an equal volume of water. The cell stroma was removed by centrifugation at $3000 \mathrm{~g}$ for $30 \mathrm{~min}$. The lysate was first pumped through a column with the SA-Sepharose equilibrated with $0.05 \mathrm{M}$-Tris-sulfate $\mathrm{pH}$ 7.5. After washing with $0.05 \mathrm{M}$-Tris-sulfate- $1 \mathrm{M}$ - sodium sulfate $\mathrm{pH}$ 7.5 , the mixture of carbonic anhydrase isoenzymes was eluted with $0.2 \mathrm{M}$-potassium thiocyanate in $0.05 \mathrm{M}$-Tris-sulfate $\mathrm{pH}$ 6.5. The enzyme containing solution was concentrated to $20 \mathrm{mg} / \mathrm{ml}$ by ultrafiltration in an Amicon Ultrafiltration cell equipped with a UM-10 membrane. The protein was precipitated by addition of solid ammonium sulfate. After washing of the precipitate with saturated ammonium sulfate solution to remove the thiocyanate the precipitate was dissolved in a minimum volume of 0.05 M-Tris-sulfate $\mathrm{pH} 7.5$ and dialyzed overnight against the same buffer.
This solution was passed through the SESepharose gel, which by a simple displacement procedure allowed separation of the isonzymes, as described in section 3.

Apocarbonic anhydrase was prepared as described by COLEMAN (3) by dialysis against 0.01 M-1,10 phenanthroline pH 5.5.

Carbonic anhydrase activity was assayed by following the hydrolysis of p-nitrophenylacetate at $348 \mathrm{~nm}$ according to the method of Armstrong et al. (2). Protein concentrations were determined from the absorbance at 280 $\mathrm{nm}$ using $\mathrm{A}_{280 \mathrm{~nm}}^{1 \%}=16.3$ and 18.7 for the $B$ and $C$ enzymes, , respectively.

Amino acid analyses were performed on the Spinco model 120 amino acid analyzer. Polyacrylamide disc gel electrophoresis was performed in $7.5 \%$ gels at $\mathrm{pH} 9.2(7)$. The electrophoresis was run at $4 \mathrm{~mA}$ per tube. The gels were stained with $1 \%$ amidoblack in $7 \%$ acetic acid and excess stain was removed by electrophoretic destaining.

\section{RESULTS AND DISCUSSION}

Both the SA-Sepharose and the SE-Sepharose gel adsorb human carbonic anhydrase (HCA) quantitatively from hemolysates of red blood cells. However, they differ in their binding capacity and ability to separate the isoenzymes. The capacities of the affinity gels were determined by passing the hemolysates over a small column of the respective affinity gel until the amount of carbonic anhydrase activity of the effluent was the same as in the starting material. After washing of the column to remove nonspecifically bound protein, the carbonic anhydrase was eluted and the amount determined from the absorbance at $280 \mathrm{~nm}$. The washing and elution procedures were as described in Figure 1. The capacity of the SASepharose gel was approximately $15 \mathrm{mg}$ of HCA per ml gel, which is about 5 times higher than for the affinity gel reported by WHITNEY (13) but equivalent to the capacity of the affinity gel described by OSBORNE and TASHIAN (11). In contrast, the SE-Sepharose gel exhibits only a capacity of $2 \mathrm{mg} \mathrm{HCA} \mathrm{pr} \mathrm{ml}$ gel. These differences in binding efficiency for affinity gels with the same essential ligand structure, the 


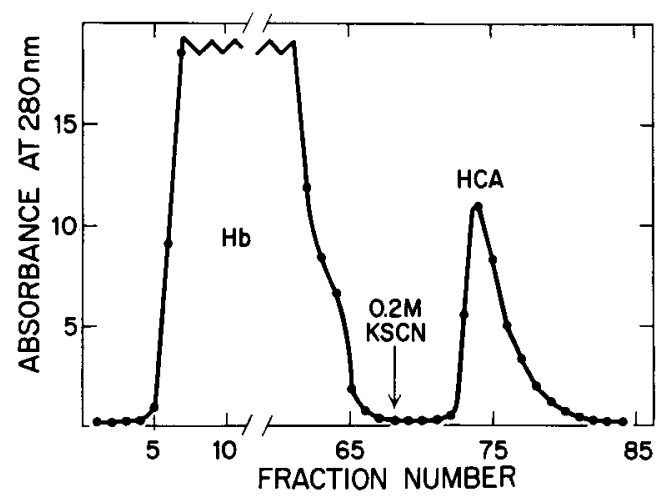

Figure 1. Purification of human carbonic anhydrase (HCA) from a hemolysate of erythrocytes on the SASepharose gel. The column $(1.5 \mathrm{~cm}$ diameter $)$ contained $10 \mathrm{ml}$ of affinity gel and was equilibrated with $0.05 \mathrm{M}$ Tris-sulfate $\mathrm{pH} 7.5$. The flow rate was 180 $\mathrm{ml} / \mathrm{hr}$ and $4 \mathrm{ml}$ fractions were collected. $50 \mathrm{ml}$ of hemolysate was diluted with $150 \mathrm{ml}$ water and passed through the column. The column was washed with $0.05 \mathrm{M}$ Tris-sulfate $-1 \mathrm{M} \mathrm{Na}_{2} \mathrm{SO}_{4} \mathrm{pH} 7.5$, and the enzymes eluted with $0.2 \mathrm{M} \mathrm{KSCN-0.05} \mathrm{M} \mathrm{Tris-sul-}$ fate $\mathrm{pH} 6.5$ as indicated.

benzenesulfonamide, show that the nature of the "spacer-arm" can have strong influence on the performance of affinity gels, an effect which also has been observed in other systems (10). Furthermore, these observations suggest that not only a sufficient length of the "spacer-arm" to allownon-restricted binding is important in affinity chromatography, but also that the specific chemicl structure of the "spacer-arm" can provide additional binding strength to the system and thereby enhance the efficiency of the affinity gel.

Figure 1 illustrates the isolation of HCA from $50 \mathrm{ml}$ hemolysate of red blood cells with the SA-Sepharose affinity gel. HCA was adsorbed to the resin at $\mathrm{pH} 7.5$. After extensive washing as described in section 2 to elute all of the hemoglobin and other nonspecific proteins, the $\mathrm{HCA}(90 \mathrm{mg})$ was eluted at $\mathrm{pH} 7.6$ by $\mathrm{SCN}^{-}$, which is a strong inhibitor of HCA and acts competitively with sulfonamides (9). Disc-gel electrophoresis (Figure 2, Gel 1) of the isolated HCA protein exhibited three bands, corresponding to the $\mathrm{A}, \mathrm{B}$ and $\mathrm{C}$ isoenzymes, respectively. The amount of HCAA varied in the individual hemolysates, and it also depended on the age of the solution. However, when stored as an ammonium sulfate precipitate, no change in the gel-electrophoresis pattern was observed. It has been suggested that HCAA is a deamidation product of HCAB (9).

For large-scale preparation of human carbonic anhydrase the SA-Sepharose derivative could be conveniently used in a batch-wise procedure. The SA-Sepharose gel, $300 \mathrm{ml}$ in two liters of hemolysate, was stirred at room temperature and after 1 hour the carbonic anhydrase was quantitatively adsorbed. The gel was collected on a sintered glass-filter and washed with 4 liters of water followed by 1 liter

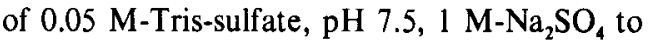
elute all the hemoglobin. The gel was then transferred to a $10 \mathrm{~cm}$ diameter column, and the HCA eluted with 1.0 liter of $0.2 \mathrm{M}-\mathrm{KSCN}$ in $0.05 \mathrm{M}$-Tris-sulfate, $\mathrm{pH}$ 6.5. After concentration to $100 \mathrm{ml}$ by ultrafiltration, and precipitation of $\mathrm{HCA}$ with solid $\left(\mathrm{NH}_{4}\right)_{2} \mathrm{SO}_{4}$, about $4.5 \mathrm{~g}$ of a hemoglobin free mixture of the isoenzymes were obtained.

The binding of sulfonamides to both isoenzymes is $\mathrm{pH}$-dependent, exhibiting weaker binding at low and high $\mathrm{pH}$ values (9). Furthermore, the $\mathrm{pH}$-dependence of the binding constants is different for the two isoenzymes, and in addition HCAC generally binds sulfonamides stronger than the B enzyme (9). Anions show improved binding with decreasing $\mathrm{pH}$, and ex-

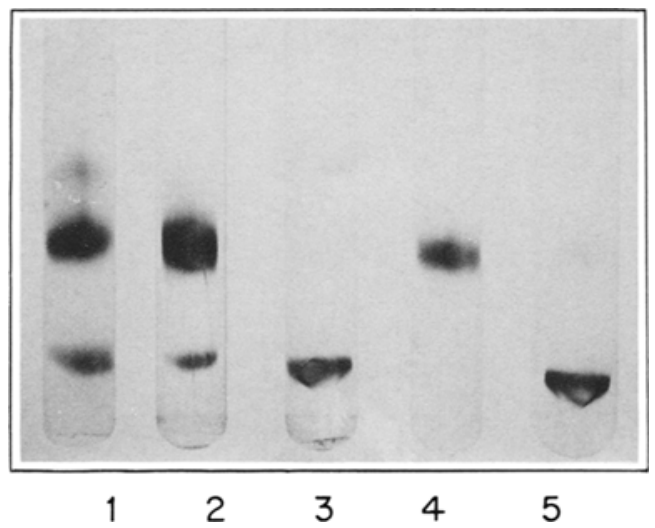

Figure 2. Polyacrylamide gels from the chromatographic peaks in Figure 1 and Figure 3. Gel 1 shows the isoenzymes isolated from the SA-Sepharose gel (Figure 1). Gel 2, 3, 4 and 5 represent the four chromatographic peaks I, II, III and IV, respectively in Figure $3 \mathrm{~A}$ and B. For details see the text. 
hibit at the same $\mathrm{pH}$ stronger binding to the $\mathrm{B}$ enzyme than to the C-enzyme (9). Hence it should be possible to exploit these differences between the two isoenzymes to design elution condition specifically for each of them. However, several attempts to elute the isoenzymes selectively using several anions at various concentrations and $\mathrm{pH}$ 's were unsuccessful. Chromatograms exhibiting two peaks could be obtained by eluting first with low concentration of $\mathrm{SCN}^{-}$, followed by elution with stepwise increases in $\mathrm{SCN}^{-}$concentration or by lowering the $\mathrm{pH}$ to improve $\mathrm{SCN}^{-}$ binding. However, these peaks always displayed long trailing edges, and analysis of the peaks by gel-electrophoresis indicated that they contained both isoenzymes in almost the same ratio as in the starting material. These findings indicate that either the binding constants for the immobolized sulfonamides are the same for the two isoenzymes or that the affinity gels contain a heterogeneous population of coupled sulfonamides with a wide range of binding constants resulting in enzyme-inhibitor complexes with overlapping stabilities for the two isoenzymes. In contrast to our results, FALKBRING et al. (6), WhitNey (13) and OsBorne and TASHIAN (11) using their respective benzenesulfonamide affinity gels could achieve separation of the isoenzymes by variation of anion concentration and $\mathrm{pH}$. These facts further emphazise the involvement of the "spacer-arm" in the binding process.

Similarly to the SA-Sepharose column, HCA was also specifically adsorbed to the SE-Sepharose, and a hemoglobin free mixture of HCAB and HCAC could be isolated using the same elution conditions as described for SA-Sepharose. However, since its capacity was only 2 $\mathrm{mg} / \mathrm{ml}$ gel it was not used for the separation of HCA from hemoglobin. However, it was noticed that the binding of the $\mathrm{C}$ enzyme to this gel was much stronger than for the $B$ enzyme, and this phenomenon was used to separate the two isoenzymes as illustrated in Fig. $3 \mathrm{~A}$ and B. In this experiment $400 \mathrm{mg}$ of $\mathrm{HCA}$ was passed through the SE-Sepharose column. When increasing amounts of the HCA mixture were appied on the column, the HCAC isoenzyme displaced the HCAB isoenzyme from the binding sites, and when an excess of HCAC, as determined by the increase in specific activity in the eluate, had been applied to the column, all the binding sites were occupied with only the C-enzyme. After washing of the column with buffer, the HCAC was eluted with $0.2 \mathrm{M} \mathrm{KSCN}$ $\mathrm{pH} 6.5$ in a yield of $30 \mathrm{mg}$. Disc gel-electrophoresis showed that the first peak mainly contained the $B$ enzyme $(360 \mathrm{mg})$ with a small amount of $\mathrm{C}$ enzyme, while the second peak contained pure $\mathrm{C}$ enzyme (Figure 2, gel 2 and $3)$. No traces of other protein bands were present. The small amount of $C$ enzyme in the HCAB enzyme fraction was easily removed by rechromatography on the SE-Sepharose (Figure $3, \mathrm{~B}$ ). The column was now unsaturated with respect to $\mathrm{HCAC}$, although still saturated with HCAB. Hence the column captured all the HCAC passing through the column, and the breakthrough peak (III) contained pure HCAB (340 mg) while the second peak eluted with $\mathrm{SCN}^{-}$now contained both isoenzymes, and in this experiment mainly HCAC $(15 \mathrm{mg})$ as determined by disc gel electrophoresis (Figure 2 , Gel 4 and 5, respectively). This procedure resulted in the isolation of homogeneous $\mathrm{HCAB}$ and HCAC isoenzymes by two affinity column runs on the SE-Sepharose.

In a large scale procedure $300 \mathrm{ml}$ of SE-Sepharose was used to fractionate about 9 grams of a mixture of $\mathrm{HCAB}$ and $\mathrm{HCAC}$, isolated by the SA-Sepharose, to homogeneous $\mathrm{HCAB}$ and HCAC isoenzymes. As a standard procedure, the affinity chromatography of the HCAC containing fractions were repeated until pure $B$ enzyme was obtained. The HCAB and HCAC bound to the column corresponding to the second peak in Figure $3 \mathbf{B}$ were not eluted but the column used directly with a new isoenzyme mixture from the SA-Sepharose column. In practical terms about 7.5 gram of $\mathrm{HCAB}$ and 1 $\mathrm{g}$ of HCAC were isolated from 9 grams of a mixture by two to three chromatographic runs, using about $300 \mathrm{ml}$ of the SE-Sepharose.

The isolated pure isoenzymes were stored as ammonium sulfate precipitates at $4^{\circ}$. The amino acid composition (Table 1) of the HCAB and HCAC isoenzymes were in excellent agreement with the compositions calculated from their respective amino acid sequences $(1,8)$. 


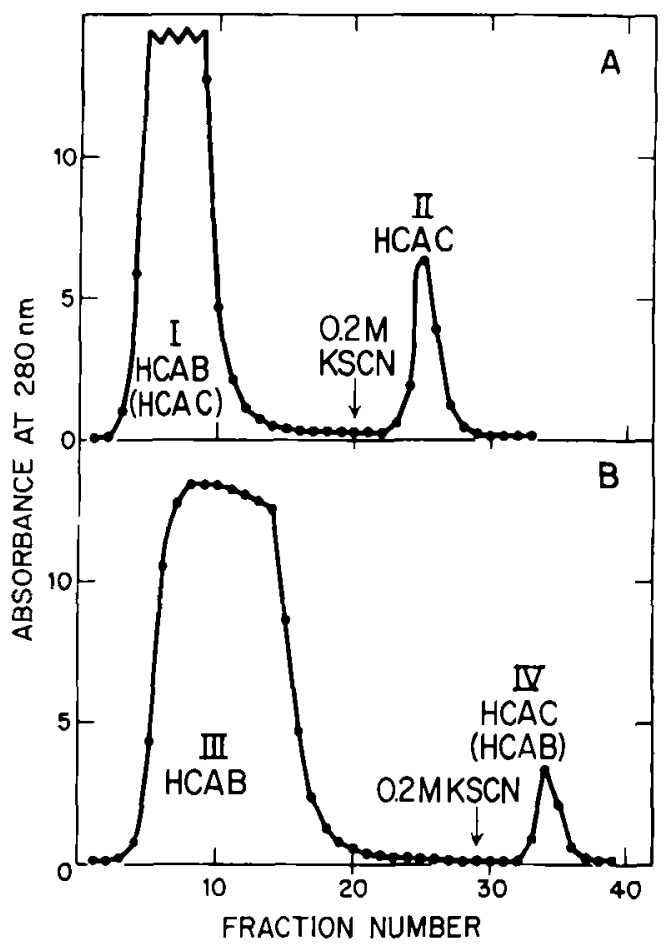

Figure 3. Separation of carbonic anhydrase B (HCAB) and $\mathrm{C}$ (HCAC) on the SE-Sepharose column. The column $(1.5 \mathrm{~cm}$ in diameter $)$ contained $15 \mathrm{ml}$ of gel and was equilibrated with $0.05 \mathrm{M}$ Trissulfate $\mathrm{pH} 7.5$. The flow rate was $180 \mathrm{ml} / \mathrm{hr}$ and $4 \mathrm{ml}$ fractions were collected. A: carbonic anhydrase (HCA) (400 mg in $6 \mathrm{ml} 0.05 \mathrm{M}$ Tris-sulfate $\mathrm{pH} 7.5$ ) which had been purified as shown in Figure 1, was applied on the column. After washing with $0.05 \mathrm{M}$ Tris-sulfate $\mathrm{pH} 7.5$, the bound carbonic anhydrase was eluted with $0.2 \mathrm{M} \mathrm{KSCN-0.05} \mathrm{M} \mathrm{Tris-sulfate} \mathrm{pH}$ 6.5 , as indicated.

B: Rechromatography of the pooled fractions from the break-through peak in A. The chromatogram was developed as in part $A$.

Furthermore, the turnover numbers for the hydrolysis of p-nitrophenyl acetate were 25 and $120 \mathrm{~min}^{-1}$ for HCAB and HCAC at $\mathrm{pH} 7.5$, respectively, which agree with the literature values for these two enzymes (12) with the assay procedure employed (2).

The binding of sulfonamides to apocarbonic anhydrase is much weaker than to native carbonic anhydrase (9), hence the affinity gel can be used to isolate metal free apocarbonic anhydrase. As shown in Figure 4 where a sample of $\mathrm{HCAB}$, in which about $40 \%$ of the active site metal had been removed by dialysis against
1,10 phenanthroline, was passed over the column the apoenzyme passed unretarded through the SA-Sepharose, and as determined from the residual activity it contained less than $1 \%$ zinc. The column was initially made metal free by washing with 3 volumes of $0.1 \mathrm{~N}-\mathrm{HCl}$ followed by glass-destilled water and metal-free dithiozone extracted 0.05 M-Tris-sulfate, $\mathrm{pH}$ 7.5. The same elution profile was obtained for the C-enzyme. Significantly, addition of stoichoimetric amounts of $\mathrm{ZnSO}_{4}$ to the apoenzyme fully restored the activity. Preparation of apocarbonic anhydrase with very low residual zinc content by the standard dialysis procedure takes up to $2-3$ weeks (3). With the present procedure this time can be reduced significantly. After dialysis for 2-3 days against 1,10 phenanthroline, where about $60 \%$ of the zinc is removed, followed by a dialysis against a metal-free $0.05 \mathrm{M}$-Tris-sulfate, $\mathrm{pH} 7.5$ buffer, to remove 1,10 phenanthroline, the mixture of apo-and $\mathrm{Zn}$-carbonic anhydrase was separated on the SA-Sepharose column as described above.

In general, the affinity gels described in the present paper should be useful for separation of all types of carbonic anhydrases with modified binding properties for sulfonamides e. $g$. the $\mathrm{Cd}$

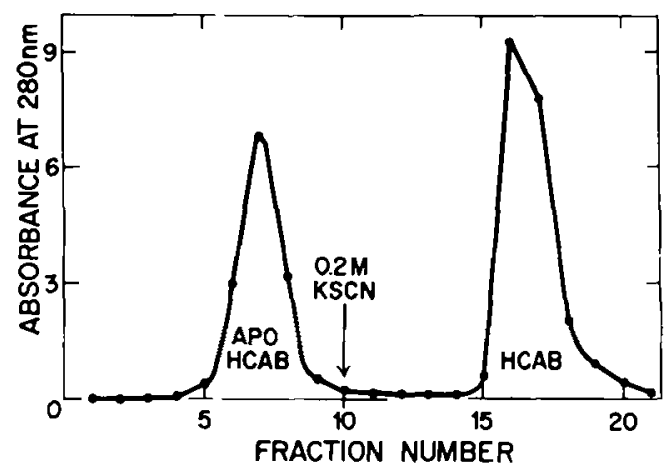

Figure 4. Separation of apocarbonic anhydrase B (Apo-HCAB) from the Zn-carbonic anhydrase (HCAB) on the SA-Sepharose column. The column ( $1.5 \mathrm{~cm}$ in diameter) contained $15 \mathrm{ml}$ of the gel, and was equilibrated with $0.05 \mathrm{M}$ Tris-sulfate $\mathrm{pH} \mathrm{7.5}$. The flow rate was $150 \mathrm{ml} / \mathrm{hr}$ and $4 \mathrm{ml}$ fractions were collected. $6 \mathrm{ml}$ of a mixture of apo-HCAB (40\%) and HCAB $(60 \%)$ in $0.05 \mathrm{M}$ Tris-sulfate $\mathrm{pH} 7.5$ was passed through the column. After washing with the same buffer the HCAB was eluted with $0.2 \mathrm{M} \mathrm{KSCN}$ $0.05 \mathrm{M}$ Tris-sulfate $\mathrm{pH} 6.5$, as indicated. 
Table I

Amino acid composition of human carbonic anhydrase $B$ and $C^{1}$

\begin{tabular}{l|c|c|c|c}
\hline & \multicolumn{2}{|c|}{ HCAB } & \multicolumn{2}{c}{ HCAC } \\
Amino acid & $\begin{array}{c}\text { Experimental } \\
\text { values (Gly=16) }\end{array}$ & $\begin{array}{c}\text { From the } \\
\text { Sequence (1) }\end{array}$ & $\begin{array}{c}\text { Experimental } \\
\text { values (Gly=22) }\end{array}$ & $\begin{array}{c}\text { From the } \\
\text { Sequence (8) }\end{array}$ \\
\hline Lysine & 18.3 & 18 & 25.8 & 24 \\
Histidine & 10.6 & 11 & 11.8 & 12 \\
Arginine & 7.0 & 7 & 7.2 & 7 \\
Aspartic acid $_{\text {Threonine }}^{2}$ & 31.1 & 31 & 30.3 & 29 \\
Serine & 14.2 & 14 & 12.7 & 12 \\
Glutamic acid & 29.9 & 30 & 20.0 & 18 \\
Proline & 22.9 & 22 & 23.8 & 24 \\
Glycine $^{2}$ & 16.9 & 17 & 16.0 & 17 \\
Alanine & 16.0 & 16 & 22.0 & 22 \\
Valine $^{3}$ & 19.3 & 19 & 14.4 & 13 \\
Methionine $^{\text {Isoleucine }}$ & 17.1 & 17 & 0.8 & 17 \\
Leucine $^{3}$ & 1.7 & 10 & 9.0 & 9 \\
Tyrosine & 8.9 & 20 & 26.8 & 8 \\
Phenylalanine & 20.5 & 8 & 7.9 & 12 \\
\hline
\end{tabular}

1) Samples of $\mathrm{HCAB}$ and $\mathrm{HCAC}$ were hydrolyzed in $6 \mathrm{~N} \mathrm{HCl}$ at $110^{\circ}$ for 22,48 and 72 hours in evacuated sealed glass tubes.

${ }^{2}$ ) The values for serine and threonine were corrected by extrapolating to zero time the values obtained at various times of hydrolysis.

3) The values of valine and isoleucine are the values obtained after 72 hours of hydrolysis.

enzyme can be separated from the Zn-enzyme (J. T. Johansen to be published). Finally, it should be mentioned that the Sepharose derivatives described have exhibited a very high degree of stability. They have been used repeatedly over one year without any losses of binding properties.

\section{ACKNOWLEDGEMENT}

The author is most grateful to $\mathrm{Mr}$. THORKILD BEENFELDT for his skilled technical assistance.

\section{REFERENCES}

1. Anderson, B., P. O. Nyman, \& L. Strid: Amino acid sequence of human carbonic anhydrase $B$. Biochem. Biophys. Res. Commun. 48: 670-677 (1972)

2. Armstrong J. McD., D. V. Myers, J. A. Verpoorte, \& J. T. EDsall: Purification and properties of human erythrocyte carbonic anhydrases. J. Biol. Chem. 241: $5137-5149$ (1966)
3. Coleman, J. E.: Human carbonic anhydrase. Protein conformation and metal ion binding. Biochemistry 4: 2644-2655 (1965)

4. Coleman, J. E.: Mechanism of action of carbonic anhydrase. Substrate, sulfonamide, and anion binding. J. Biol. Chem. 242: 5112-5119 (1967)

5. Cuatracasas, P.: Protein purification by affinity chromatography. Derivatizations of agarose and polyacrylamide beads. J. Biol. Chem. 245: 30593065 (1970)

6. Falkbring, S. O., P. O. Gothe, P. O. Nyman, L. SUNDBi:RG \& J. PORATH.: Affinity chromatography of carbonic anhydrase. FEBS Letters 24: 229-235 (1972)

7. GoRdon, A. H.: Electrophoresis of proteins in polyacrylamide and starch gels. p. 52-55, NorthHolland Publishing Company, Amsterdam (1969)

8. Henderson, L. E., D. Henrikson \& P. O. Nyman: Amino acid sequence of human erythrocyte carbonic anhydrase C. Biochem. Biophys. Res. Commun. 52: 1388-1394 (1973)

9. Lindskog, S., L. E. Henderson, K. K. Kannan, A. Liljas, P. O. Nyman \& B. Strandererg: Carbonic anhydrase. In The Enzymes. Vol. 5, p. 587. Ed. P. D. Boyer, Academic Press, New York (1971) 
10. Lowe C. R. \& P. O. G. Dean: Affinity chromatography. p. 23-24 John Wiley and Sons, New York (1974)

11. Osborne, W. R. \& R. E. Tashian: An improved method for the purification of carbonic anhydrase isozymes by affinity chromatography. Anal. Biochem. 64: 297-303 (1975)
12. Verpoorte, J. A., S. Mehta, and J. T. Edsall: Esterase activities of human carbonic anhydrase B and C.J. Biol. Chem. 242:4221-4229 (1967)

13. Whitney, P. L.: Affinity chromatography of carbonic anhydrase. Anal. Biochem. 57: 467-476 (1974) 